\title{
Surgical Outcome and Improvement in Quality of Life after Microvascular Decompression for Hemifacial Spasms: A Case Series Assessment Using a Validated Disease-Specific Scale
}

\author{
Dibyendu K. Ray Diaa Bahgat Shirley McCartney Kim J. Burchiel \\ Department of Neurological Surgery, Oregon Health \& Science University, Portland, Oreg., USA
}

\section{Key Words}

Hemifacial spasm • Microvascular decompression • Quality of life

\begin{abstract}
Background: Hemifacial spasm (HFS) is a movement disorder characterized by intermittent, involuntary clonic or tonic-clonic contractions of muscles innervated by the ipsilateral facial nerve. Recent studies have documented change in quality of life after HFS management with botulinum toxin injection. However, we failed to locate any study that documented change in quality of life after surgical management with retrosigmoid microvascular decompression (MVD). Methods: Our study objectives were 3-fold. Firstly, to use a disease-specific, validated quality of life assessment scale to document any change in quality of life after MVD for HFS. Secondly, to determine the time period in which the majority of patients undergoing MVD could be expected to benefit from surgery. Finally, to determine factors affecting the postoperative quality of life following MVD. A retrospective analysis of HFS patients treated with MVD at a single institution by a single surgeon (K.J.B.) between January 2000 and December 2007 was undertaken. A modification of a previously developed validated disease-specific quality of life as-
\end{abstract}

sessment scale that included the addition of a parameter for difficulty in sleep was used to assess quality of life before and after surgery. Results: A total of 21 patients (14 female and 7 male) underwent treatment as specified. Eighty-five percent $(17 / 20)$ of the patients reported prolonged remission of symptoms (mean follow-up period $=4.15$ years). Five percent $(1 / 20)$ reported occasional recurrence of twitches. The overall mean quality of life score improved from 11.1 preoperatively to 2.2 postoperatively. Conclusions: MVD offers significant and prolonged improvement in quality of life for the HFS patients we studied, as measured using a disease-specific, validated quality of life assessment scale. Postoperative quality of life, however, was strongly influenced by both the success of surgery in resolving the symptoms and the absence of any permanent complications of surgery.

Copyright $\odot 2010$ S. Karger AG, Basel

\section{Introduction}

Hemifacial spasm (HFS) is a movement disorder characterized by intermittent, involuntary clonic or tonicclonic contractions of muscles innervated by the ipsilateral facial nerve, with the contractions being asymmetrical and asynchronous. Typically, HFS onset is in the fifth

\section{KARGER}

Fax +41613061234 E-Mail karger@karger.ch www.karger.com

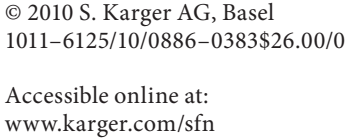

Kim J. Burchiel, MD, FACS

Department of Neurological Surgery (CH8N), Oregon Health \& Science University 3303 SW Bond Ave.

Portland, OR 97239 (USA)

Tel. +1 503494 4314, Fax +1 503346 6810, E-Mail burchiek@ ohsu.edu 
and sixth decades of life, though young onset ( $\leq 30$ years) has been described in about $6.5 \%$ of cases $[1,2]$. The symptoms are essentially unilateral; bilateral involvement is rarely reported ( $0.6-5 \%$ of cases) [3-6]. The symptoms generally commence in the periorbital muscles, usually the lower eyelid, and then progress to affect other muscles of the face innervated by the facial nerve, including the platysma [7]. Progression in frequency and severity of attacks also occurs. Vision may become a concern, if there is diminished visual acuity in the contralateral eye.

It is well known that the quality of life is significantly impaired in HFS patients [8-14]. While association of HFS with depressive symptoms, social anxiety and obsessive-compulsive symptoms have been described, few, if any, studies have attempted to document any improvement in quality of life, with a standardized scale, in HFS patients undergoing surgery, specifically microvascular decompression (MVD) [15-19]. It has been observed that mere functional improvement after surgery may not translate into improvement in quality of life, thereby raising the importance of complementary assessment of quality of life gains as a measure of the success of surgery
$[1,11]$. In this study, we have used a validated, diseasespecific scale to assess improvement in quality of life in patients undergoing MVD for HFS at our institution [16].

\section{Materials and Methods}

A retrospective case series analysis of patients who underwent surgical management of HFS at Oregon Health \& Science University (OHSU) between January 2000 and December 2007 was un-

Table 1a. Patient data

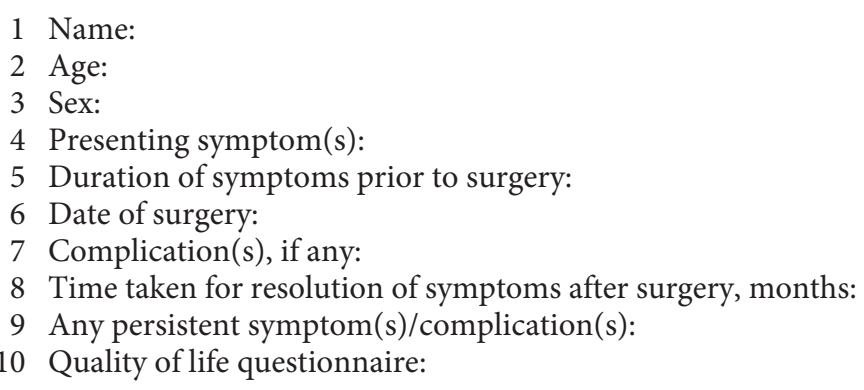

Table 1b. Assessment

\begin{tabular}{|c|c|c|c|c|c|}
\hline & Parameter & Observed when & Yes/no & Severity & $\begin{array}{l}\text { If present prior to treatment, how long did } \\
\text { it take to resolve after treatment, months }\end{array}$ \\
\hline 1 & Difficulty in driving & $\begin{array}{l}\text { before surgery } \\
\text { after surgery }\end{array}$ & & & \\
\hline 2 & Difficulty in reading & $\begin{array}{l}\text { before surgery } \\
\text { after surgery }\end{array}$ & & & \\
\hline 3 & Difficulty in watching television/movies & $\begin{array}{l}\text { before surgery } \\
\text { after surgery }\end{array}$ & & & \\
\hline 4 & Felt depressed & $\begin{array}{l}\text { before surgery } \\
\text { after surgery }\end{array}$ & & & \\
\hline 5 & Avoided eye contact & $\begin{array}{l}\text { before surgery } \\
\text { after surgery }\end{array}$ & & & \\
\hline 6 & Felt embarrassed about having the condition & $\begin{array}{l}\text { before surgery } \\
\text { after surgery }\end{array}$ & & & \\
\hline 7 & Felt worried about others' reaction to you & $\begin{array}{l}\text { before surgery } \\
\text { after surgery }\end{array}$ & & & \\
\hline 8 & Sleep disturbance & $\begin{array}{l}\text { before surgery } \\
\text { after surgery }\end{array}$ & & & \\
\hline
\end{tabular}

The severity should be graded as follows: 0 = normal; 1 = slight disability; 2 = moderate disability, no functional impairment; $3=$ moderate disability, functional impairment; 4 = severely incapacitated. 
Table 2. Cumulative pre- and postoperative quality of life assessment scores $(n=20)$

\begin{tabular}{lll}
\hline Parameter & $\begin{array}{l}\text { Total pre- } \\
\text { operative score }\end{array}$ & $\begin{array}{l}\text { Total post- } \\
\text { operative score }\end{array}$ \\
\hline Difficulty in driving & 18 & 6 \\
Difficulty in reading & 25 & 8 \\
Difficulty in watching television & 15 & 3 \\
Felt depressed & 28 & 5 \\
Avoided eye contact & 33 & 6 \\
Felt embarrassed about having the condition & 45 & 9 \\
Felt worried about others' reactions & 40 & 7 \\
Sleep disturbance & 18 & 1 \\
\hline
\end{tabular}

Severity was graded as follows: $0=$ normal; 1 = slight disability; 2 = moderate disability, no functional impairment; 3 = moderate disability, functional impairment; 4 = severely incapacitated. dertaken. All patients had undergone standard MVD using a retrosigmoid approach, and Teflon was used to pack the offending vessel away from the affected facial nerve at the site of impingement. The study was approved by the OHSU institutional review board.

A previously developed validated disease-specific quality of life assessment scale [16] was modified to include a parameter to measure difficulty in sleep, to assess quality of life before and after MVD (table 1). The patients were contacted by mail and then by telephone, and after verbally obtaining permission they were asked to scale their quality of life before and after their MVD surgery. Difficulty experienced by the patients was graded on a scale of $0-4$ as follows: $0=$ normal, $1=$ slight disability, $2=$ moderate disability, no functional impairment, 3 = moderate disability, functional impairment, 4 = severely incapacitated.

All patient data were collected in a Microsoft Excel for Windows file and StatView (SAS Institute Inc.) for Apple Macintosh was used for statistical analysis. Multiple regression analysis was attempted to identify predictors of outcome and Fisher's exact test was used for categorical data analysis and to identify any correlation between postoperative quality of life score and age, sex, duration of symptoms, follow-up, preoperative quality of life score and resolution of symptoms.

\section{Results}

A total of 21 patients (14 female and 7 male) who underwent treatment at OHSU by the senior author (K.J.B.) during the time period specified were identified. Their mean age was 51 years (range $=26-80$ years). The symptom duration as reported by 20 patients was $1-15$ years (mean duration $=6.2$ years). One patient was unsure of the symptom duration. Of the 21 patients, 5 had rightsided symptoms (24\%) and 16 had left-sided symptoms (76\%). Four patients presented while symptoms were confined to the periocular region, 1 patient had perioral twitches, and 1 patient had both periocular and perioral twitches. The remaining 11 patients reported facial twitches and 4 had full-blown HFS. Twenty of 21 patients who underwent MVD were available for follow-up (the patients were contacted by telephone). The mean followup was 4.15 years (range $=0.75-8.5$ years). Of these 20 patients, 17 (85\%) experienced complete resolution of symptoms (range $=$ immediate to 9 months) at the time of follow-up (that is when they were contacted retrospectively), while the 3 remaining patients experienced no improvement in symptoms. Of note, 2 of the 17 patients experienced minimal (1-point decrease in overall pain severity score) improvement. Fifteen patients (83\%) experienced early resolution of symptoms [13 patients (72\%) experiencing immediate relief and 2 (11\%) having resolution of symptoms within the first week of surgery]. There were 9 complications (43\%) following surgery; 1 patient had a transient partial hearing loss of $20 \%$, which spontaneously resolved in 2 months, 1 patient had a transient facial weakness, which spontaneously resolved within 2 weeks, 1 patient suffered from excessive postsurgical wound site pain, 1 patient felt wound site tightness for 3 months following surgery, 1 patient had a wound cerebrospinal fluid (CSF) leak, 1 patient had paradoxical CSF rhinorrhea, both of which were managed by surgical re-exploration and leak repair, 2 patients had permanent hearing loss following surgery, with one also suffering from facial weakness, and 1 patient had intermittent recurrences after 1 year of relief. Cumulative preand postoperative quality of life assessment scores for each different parameter were obtained (table 2). Of note, the preoperative quality of life scores were highest for social and emotional parameters (felt embarrassed about 
Table 3. Individual (cumulative) pre- and postoperative quality of life assessment scores $(\mathrm{n}=20)$

\begin{tabular}{lrl}
\hline Patient ID & $\begin{array}{l}\text { Total pre- } \\
\text { operative score }\end{array}$ & $\begin{array}{l}\text { Total post- } \\
\text { operative score }\end{array}$ \\
\hline 1 & 14 & 0 \\
2 & 15 & 21 \\
3 & 7 & 0 \\
4 & 6 & 0 \\
5 & 21 & 0 \\
6 & 0 & 0 \\
7 & 6 & 9 \\
8 & 15 & 1 \\
9 & 16 & 0 \\
10 & 21 & 0 \\
11 & 17 & 0 \\
12 & 9 & 0 \\
13 & 9 & 8 \\
14 & 9 & 0 \\
15 & 10 & 0 \\
16 & 22 & 0 \\
17 & 13 & 0 \\
18 & 3 & 2 \\
19 & 8 & 0 \\
20 & 1 & 4 \\
\hline
\end{tabular}

Cumulative severity scores for: difficulty in driving, reading and watching television/movies, avoiding eye contact, feeling depressed, embarrassed about having the condition and worried about others' reactions, and sleep disturbance.

having the condition, felt worried about others' reactions and avoided eye contact), these scores dramatically declined after MVD treatment. Multiple regression analysis revealed no outcome correlation except that noted below.

The preoperative quality of life assessment score ranged from 0 to $22($ mean $=11.1)$, and the postoperative score ranged from 0 to 21 (mean $=2.2)$ (table 3$)$. It was noted that the psychological perceptions of the patient regarding his/her appearance and the individual's perception of others' possible reaction had the greatest bearing on patient quality of life. The maximum improvement was in the patients' feeling of embarrassment and their perception of others' reaction to them, which improved from mean scores of 2.25 and 2 to 0.45 and 0.35 , respectively, for our study group. Further analysis of the postoperative scores revealed that if the two patients who did not experience symptomatic improvement were excluded from the postoperative score assessment, the postoperative score range changed to $0-9$ (mean $=0.83)$. A positive correlation existed between the postoperative quality of life score and resolution of symptoms ( $\mathrm{p}$ value $<0.001)$. Of note, the patients' functional status worsened or did not show expected improvement if the patient did not experience resolution of symptoms after surgery and if there were postsurgical complications.

\section{Discussion}

Few studies have been undertaken to elucidate the prevalence of HFS in the general population. An US study revealed an average prevalence of 11 per 100,000 population [20], while a Norwegian study reported a prevalence rate of 9.8 per 100,000 people $[20,21]$. Both studies demonstrated an increased prevalence in women with an average female to male ratio of approximately $2: 1$. This may be due to the smaller cranial volume in females leading to overcrowding of the posterior fossa structures. The prevalence is reportedly higher in some Asian populations [7, 22]. A recent 3-dimensional magnetic resonance (MR) volumetric analysis demonstrated a lower volume of CSF in the posterior fossa of HFS patients when compared for age, sex and race with matched controls [23]. Familial HFS, which has been described to have definite left-side predominance as opposed to nonselective laterality of sporadic HFS, has also been reported, and though no definite inheritance pattern has been found, it is thought to be autosomal dominant with low penetrance $[5,24]$. The role of neurovascular conflict has also been described in such cases [25].

Though no apparent cause may be found in some cases, the most common finding is a focal compression of the root exit zone of the facial nerve by an aberrant, atherosclerotic or ectatic vessel, commonly the posterior inferior cerebellar artery or anterior inferior cerebellar artery, or a combination of anterior inferior cerebellar artery and posterior inferior cerbellar artery, or the vertebral artery causing focal demyelination resulting in 'ephaptic transmission' [26]. It is therefore not surprising that HFS has also been termed a hyperactive dysfunction syndrome of the facial nerve [27]. Antidromic stimulation of the facial nucleus is thought to produce a 'kindling effect'. Neurovascular conflict as a probable cause was first suggested in 1947 by Campbell and Keedy [28]. MR imaging and MR angiography studies have made it possible to compare the incidence of neurovascular conflict in the affected side with a control population; between 65 and $85 \%$ ipsilaterally in HFS patients, compared to $7 \%$ in a control population $[29,30]$. Studies that include surgical 
correlation have reported an even higher incidence (96$100 \%$ ) of neurovascular impingement in patients undergoing MVD for HFS [26, 31]. However, a 3T MR imaging study has revealed neurovascular contact in approximately $78.6 \%$ of asymptomatic cases [32].

Evidence in favor of neurovascular contact as the causative factor of HFS naturally led MVD to be envisioned as a procedure that could potentially reverse the evident pathology. The procedure was first proposed by Gardner and Sava in 1962 [33, 34], who considered HFS as a reversible pathophysiologic state. The procedure was later popularized by Jannetta et al. [35-37]. Though the cure rates following MVD have been described as good (between 62 and $100 \%$ of cases), it is well known that the quality of life is significantly impaired in HFS patients [8-14].

Given an evolving consensus on optimal utilization of health care resources, it is possible that in the not too distant future, the parameter of improvement in quality of life for the management of a particular disease or condition by a particular modality shall play an increasing role in determining its acceptance by the medical field. The concept of quality of life assessment in neurological disorders is not new, but the use of such assessment has often been limited to chronic illnesses like Parkinson's disease and multiple sclerosis [38]. HFS per se has been considered a reversible pathophysiologic state [33] and may also be associated with the syndrome of combined hyperactive dysfunction of cranial nerves $[33,39,40]$. Though usually without any disabling clinical symptoms, the psychosocial burden of the disease cannot be ignored [15, 17-19].

There are few studies that document the degree of impairment of functional status of patients with HFS. A pertinent reason might be the nature of the disease, which does not lend itself to the use of commonly utilized scales for assessment of quality of life in patients with neurological disorders as practical. For the purpose of this study, we used a modified HFS-7 scale to measure mobility, activities of daily living, emotional well-being and stigma. Our scale specifically measured: difficulty in driving, reading and watching television/movies, feeling depressed, embarrassed about having the condition and worried about other's reactions, avoiding eye contact and sleep disturbance (table 1). The HFS-7 scale had been described by Tan et al. [16] as a short, practical, validated quality of life scale specific to HFS patients. The HFS-7 scale has been found to correlate well with the short form (36) health survey generic quality of life scale [16]. A Chinese version of a quality of life scale has been developed and the outcome of patients treated with botulinum tox- in documented [41], but we were unable to locate any study documenting the changes in quality of life of patients undergoing MVD for HFS, prompting us to undertake this retrospective study. In a study to assess the improvement in quality of life of HFS patients after botulinum toxin injection treatment, it was observed that functional improvement did not directly translate into quality of life gains [1]. This might have been due either to the perceived side effects of botulinum treatment, including partial paralysis of the muscles injected, or due to the necessity of repeated treatment to maintain the effect.

Our present study was therefore undertaken on patients who had undergone a more definite treatment in the form of MVD than in patients with HFS per se. A positive correlation between the presence of a vascular indentation at the root exit zone and a good outcome after MVD for HFS [42] has been known for some time and an intraoperative finding of a root exit zone indentation has been described as a favorable prognostic factor [42, 43]. Our success rate of $90 \%$, determined by complete resolution of symptoms, compares favorably with the reported success rates of $82-92 \%$ in some recent series [ 9 , 42, 44-46]. There are conflicting data regarding time taken for resolution of symptoms and preservation of the effects of surgery. While Shin et al. [44] reported that the success rates rose from $61.1 \%$ in the first week after surgery to $82.7 \%$ at 6 months, Moffat et al. [13] noticed that they dropped from $93.3 \%$ at the 3-month follow-up to $80 \%$ at $>6$ months of follow-up. Most patients (75\%) in our study achieved early remission of symptoms (within the first week after surgery), and the remission was maintained for a prolonged period. By 3 months, $85 \%$ of our patients had achieved complete remission of symptoms. It took approximately 9 months for 1 patient (5\%) to become symptom free. Remission onset in the postoperative period did not seem to have any correlation with duration of illness. However, given the small sample size of our study, it was not possible to determine with convincing statistical accuracy whether the degree of severity of preoperative symptoms had any influence on either the success of surgery or the time taken for resolution of symptoms. Our complication rates regarding partial (1 patient) and complete ( 2 patients) hearing loss, and partial facial weakness (1 patient) also compares favorably with the statistics reported by other authors $[9,13]$. Potential limitations of our study include the small patient cohort and the limited value in asking patients to recall their pre- and postoperative pain, retrospectively, many years later. These limitations should be addressed with 
future studies. For example, use of our preliminary data to plan a larger prospective study that compared quality of life before and after MVD would be prudent for future consideration.

\section{Conclusions}

In this study, we were able to use a modified diseasespecific, validated quality of life assessment scale to document any change in quality of life after MVD for HFS. More than $80 \%$ of the patients achieved early resolution of symptoms after surgery (1 week). We found that improvement in quality of life was not only related to the functional improvement in the symptoms of HFS but also to absence of any permanent postoperative complications. Patients with permanent complications attributable to surgery demonstrated a lower postoperative quality of life, which though not attributable to the disease per se but to the treatment thereof, nevertheless affected the life of the individual profoundly. However, patients in whom the surgery was successful and without any complications enjoyed a remarkable improvement in all aspects of their quality of life scores (the mean preoperative quality of life score fell from 11.1 to 2.2 postoperatively). This reinforces our belief that MVD not only provides fast and long-term relief for HFS patients but also improves the quality of life in such patients, more so than that achieved by other forms of management like administration of botulinum toxin.

\section{References}

1 Reimer J, Gilg K, Karow A, Esser J, Franke GH: Health-related quality of life in blepharospasm or hemifacial spasm. Acta Neurol Scand 2005;111:64-70.

$\checkmark 2$ Tan EK, Chan LL: Young onset hemifacial spasm. Acta Neurol Scand 2006;114:59-62.

-3 Tan EK, Jankovic J: Bilateral hemifacial spasm: a report of five cases and a literature review. Mov Disord 1999;14:345-349.

$\checkmark 4$ Felicio AC, Godeiro-Junior Cde O, Borges V, Silva SM, Ferraz HB: Bilateral hemifacial spasm: a series of 10 patients with literature review. Parkinsonism Relat Disord 2008;14: 154-156.

5 Miwa H, Mizuno Y, Kondo T: Familial hemifacial spasm: report of cases and review of literature. J Neurol Sci 2002;193:97-102.

6 Rosso AL, Mattos JP, Fogel LM, Novis SA: Bilateral hemifacial spasm. Mov Disord 1994;9:236-237.

7 Au WL, Tan LC, Tan AK: Hemifacial spasm in Singapore: clinical characteristics and patients' perceptions. Ann Acad Med Singapore 2004;33:324-328.

$\checkmark 8$ Samii M, Gunther T, Iaconetta G, Muehling M, Vorkapic P, Samii A: Microvascular decompression to treat hemifacial spasm: longterm results for a consecutive series of 143 patients. Neurosurgery 2002;50:712-718; discussion 718-719.

-9 Illingworth RD, Porter DG, Jakubowski J: Hemifacial spasm: a prospective long-term follow-up of 83 cases treated by microvascular decompression at two neurosurgical centres in the United Kingdom. J Neurol Neurosurg Psychiatry 1996;60:72-77.

10 Park JS, Kong DS, Lee JA, Park K: Hemifacial spasm: neurovascular compressive patterns and surgical significance. Acta Neurochir (Wien) 2008;150:235-241; discussion 241
11 Heuser K, Kerty E, Eide PK, Cvancarova M, Dietrichs E: Microvascular decompression for hemifacial spasm: postoperative neurologic follow-up and evaluation of life quality. Eur J Neurol 2007;14:335-340.

12 Zhang KW, Shun ZT: Microvascular decompression by the retrosigmoid approach for idiopathic hemifacial spasm: experience with 300 cases. Ann Otol Rhinol Laryngol 1995;104:610-612.

13 Moffat DA, Durvasula VS, Stevens King A, De R, Hardy DG: Outcome following retrosigmoid microvascular decompression of the facial nerve for hemifacial spasm. J Laryngol Otol 2005; 119:779-783.

14 Choi SJ SK, Sung WH, Lee JS, Kang JK, Choi CR: The clinical analysis of 75 patients which were operated on MVD. J Korean Neurosurg Soc 1990;19:506-512.

15 Broocks A, Thiel A, Angerstein D, Dressler D: Higher prevalence of obsessive-compulsive symptoms in patients with blepharospasm than in patients with hemifacial spasm. Am J Psychiatry 1998;155:555-557.

16 Tan EK, Fook-Chong S, Lum SY, Thumboo J: Validation of a short disease-specific quality of life scale for hemifacial spasm: correlation with SF-36. J Neurol Neurosurg Psychiatry 2005;76:1707-1710.

-17 Tan EK, Lum SY, Fook-Chong S, Chan LL, Gabriel C, Lim L: Behind the facial twitch: depressive symptoms in hemifacial spasm. Parkinsonism Relat Disord 2005;11:241245.

-18 Serrano-Duenas M: Hemifacial spasm, quality of life and depression. Rev Neurol 1999; 29:1108-1111.

19 Ozel-Kizil ET, Akbostanci MC, Ozguven HD, Atbasoglu EC: Secondary social anxiety in hyperkinesias. Mov Disord 2008;23:641645.
20 Auger RG, Whisnant JP: Hemifacial spasm in Rochester and Olmsted County, Minnesota, 1960 to 1984. Arch Neurol 1990;47: 1233-1234.

-21 Nilsen B, Le KD, Dietrichs E: Prevalence of hemifacial spasm in Oslo, Norway. Neurology 2004;63:1532-1533.

22 Tan NC, Chan LL, Tan EK: Hemifacial spasm and involuntary facial movements. QJM 2002;95:493-500.

23 Chan LL, Ng KM, Fook-Chong S, Lo YL, Tan EK: Three-dimensional MR volumetric analysis of the posterior fossa CSF space in hemifacial spasm. Neurology 2009;73:10541057.

24 Carter JB, Patrinely JR, Jankovic J, McCrary JA 3rd, Boniuk M: Familial hemifacial spasm. Arch Ophthalmol 1990;108:249-250.

25 Lagalla G, Logullo F, Di Bella P, Haghighipour R, Provinciali L: Familial hemifacial spasm and determinants of late onset. Neurol Sci 2010;31:17-22.

26 Girard N, Poncet M, Caces F, Tallon Y, Chays A, Martin-Bouyer P, Magnan J, Raybaud C: Three-dimensional MRI of hemifacial spasm with surgical correlation. Neuroradiology 1997;39:46-51.

$>27$ Jannetta PJ, Abbasy M, Maroon JC, Ramos FM, Albin MS: Etiology and definitive microsurgical treatment of hemifacial spasm: operative techniques and results in 47 patients. J Neurosurg 1977;47:321-328

28 Campbell E, Keedy C: Hemifacial spasm: a note on the etiology in two cases. J Neurosurg 1947;4:342-347.

29 Adler CH, Zimmerman RA, Savino PJ, Bernardi B, Bosley TM, Sergott RC: Hemifacial spasm: evaluation by magnetic resonance imaging and magnetic resonance tomographic angiography. Ann Neurol 1992;32: 502-506. 
-30 Jespersen JH, Dupont E, Gelineck J, Lundorf E: Hemifacial spasm: magnetic resonance angiography. Acta Neurol Scand 1996;93:35-38.

-31 Campos-Benitez M, Kaufmann AM: Neurovascular compression findings in hemifacial spasm. J Neurosurg 2008;109:416-420.

-32 Kakizawa Y, Seguchi T, Kodama K, Ogiwara T, Sasaki T, Goto T, Hongo K: Anatomical study of the trigeminal and facial cranial nerves with the aid of 3.0-tesla magnetic resonance imaging. J Neurosurg 2008;108:483490.

-33 Gardner W, Sava G: Hemifacial spasm - a reversible pathophysiologic state. J Neurosurg 1962;19:240-247.

34 Gardner WJ: Concerning the mechanism of trigeminal neuralgia and hemifacial spasm. J Neurosurg 1962;19:947-958.

35 Jannetta PJ, Hackett E, Ruby JR: Electromyographic and electron microscopic correlates in hemifacial spasm treated by microsurgical relief of neurovascular compression. Surg Forum 1970;21:449-451.

-36 Jannetta PJ: Trigeminal neuralgia and hemifacial spasm - etiology and definitive treatment. Trans Am Neurol Assoc 1975;100:8991.
Jannetta PJ: The cause of hemifacial spasm: definitive microsurgical treatment at the brainstem in 31 patients. Trans Sect Otolaryngol Am Acad Ophthalmol Otolaryngol 1975;80:319-322.

38 Meyers AR, Gage H, Hendricks A: Healthrelated quality of life in neurology. Arch Neurol 2000;57:1224-1227.

39 Kobata H, Kondo A, Iwasaki K, Nishioka T: Combined hyperactive dysfunction syndrome of the cranial nerves: trigeminal neuralgia, hemifacial spasm, and glossopharyngeal neuralgia: 11-year experience and review. Neurosurgery 1998;43:1351-1361; discussion 1361-1362.

40 Yang KH, Na JH, Kong DS, Park K: Combined hyperactive dysfunction syndrome of the cranial nerves. J Korean Neurosurg Soc 2009;46:351-354.

41 Huang YC, Fan JY, Ro LS, Lyu RK, Chang HS, Chen ST, Hsu WC, Chen CM, Wu YR Validation of a Chinese version of diseasespecific quality of life scale (HFS-36) for hemifacial spasm in Taiwan. Health Qual Life Outcomes 2009;7:104.
42 Chung SS, Chang JW, Kim SH, Chang JH, Park YG, Kim DI: Microvascular decompression of the facial nerve for the treatment of hemifacial spasm: preoperative magnetic resonance imaging related to clinical outcomes. Acta Neurochir (Wien) 2000;142: 901-906; discussion 907.

43 Kim HR, Rhee DJ, Kong DS, Park K: Prognostic factors of hemifacial spasm after microvascular decompression. J Korean Neurosurg Soc 2009; 45:336-340.

44 Shin JC, Chung UH, Kim YC, Park CI: Prospective study of microvascular decompression in hemifacial spasm. Neurosurgery 1997;40:730-734; discussion 734735.

45 Chang JW, Chang JH, Park YG, Chung SS: Microvascular decompression of the facial nerve for hemifacial spasm in youth. Childs Nerv Syst 2001;17:309-312.

46 Chung SS, Chang JH, Choi JY, Chang JW, Park YG: Microvascular decompression for hemifacial spasm: a long-term follow-up of 1169 consecutive cases. Stereotact Funct Neurosurg 2001;77:190-193.

\section{Erratum}

A technical error occurred in figure 2 during the data processing of the print version of the article 'Successful Treatment of a Skull Base Malignant Rhabdoid Tumor with Surgery, Chemotherapy and Gamma Knife-Based Stereotactic Radiosurgery in a Young Child' by Witt et al. (Stereotact Funct Neurosurg 2007;85:310-313). The correct figure $2 \mathrm{a}, \mathrm{b}$ is printed below:
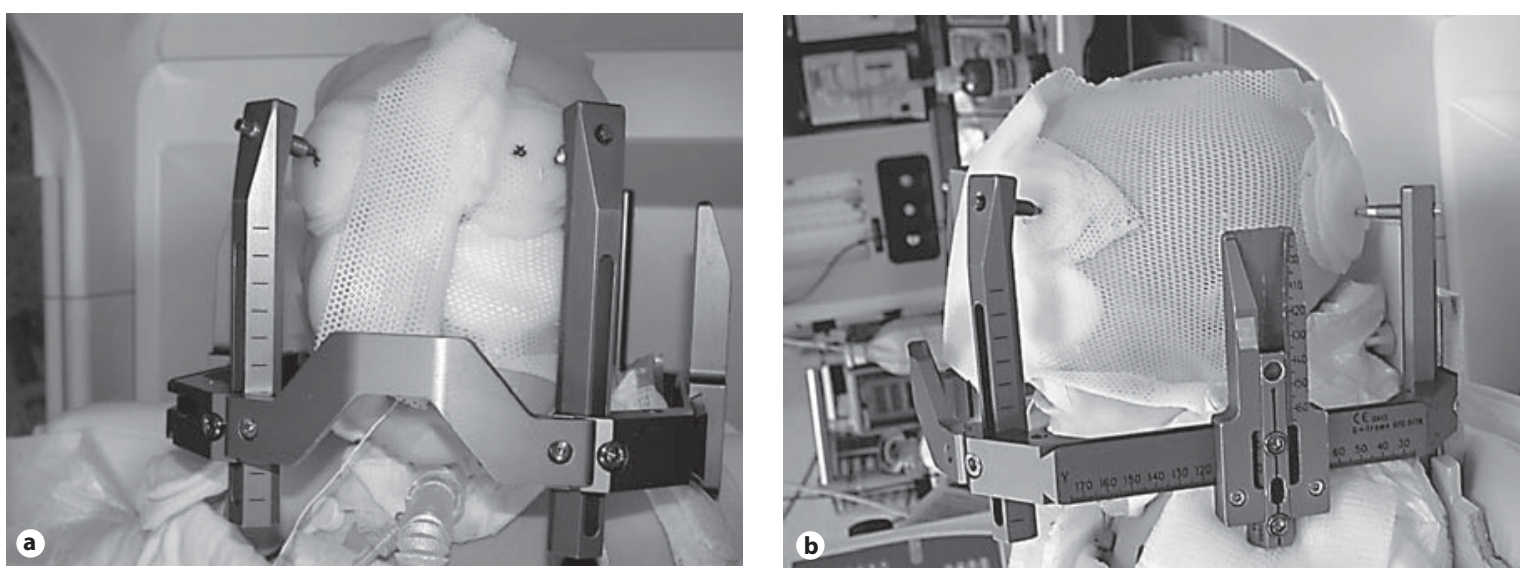

Fig. 2. a, b Pictures showing the device typically used for headframe immobilization for very young children (this was not the patient described in the case report). 